\title{
PENINGKATAN KOMPETENSI LULULSAN SISWA PROGRAM STUDI TEKNIK KOMPUTER JARINGAN SMK ROSMA KARAWANG MELALUI PELATIHAN DEVELOPMENT APLIKASI GAME ANDROID
}

\author{
Rahmat Gunawan ${ }^{1}$, Rini Malfiany², Yahya Suherman ${ }^{3}$, Meiniarti ${ }^{4}$ \\ 1,2,3,4Program Studi Manajemen Informatika, STMIK ROSMA \\ Email : ${ }^{1}$ rahmat@rosma.ac.id, ${ }^{2}$ rini.malfiany@dosen.rosma.ac.id, \\ ${ }^{3}$ yahya.suherman@dosen.rosma.ac.id, ${ }^{4}$ meiniarti@dosen.rosma.ac.id
}

Diterima : 09-06-2021, Di publikasikan : 16-06-2021

\begin{abstract}
Abstrak
Meningkatnya pengguna Android di masyarakat, mendorong industri untuk mengaplikasikan beberapa proses bisnisnya melalui aplikasi Android. Kesempatan ini, patut di ambil oleh kalangan pendidikan khususnya Sekolah Menengah Kejuruan(SMK). SMK yang memiliki program pendidikan base komputer, setidaknya dapat mengaplikasikannya pada kurikulum . Namun, belum semua dapat mengimplementasikannya, hal ini dapat disebabkan karena minimnya spesifikasi komputer yang ada di sekolah, sehingga sulit untuk implementasi pembelajaran developer Android. Pelatihan Developer Game Android menjadi salah satu potensi untuk meningkatkan kompetensi siswa SMK. Pada kegiatan ini, mitra dari pelatihan developmen aplikasi game android adalah program studi Teknik Komputer Jaringan(TKJ) SMK ROSMA KARAWANG. Tujuan dari kegiatan ini adalah memberikan pamahaman dasar untuk membuat aplikasi game andorid, sehingga dapat mengembangkan kompetensi siswa prodi TKJ dan meningkatkan penyerapan lulusan SMK di Industri. Hasil dari kegiatan ini berupa produk aplikasi game android yang di kembangkan oleh peserta yang dapat di instal di mobile phone masing - masing peserta. Implikasi dari kegiatan ini adalah, meningkatkan minat belajar siswa dalam development aplikasi base android yang berdampak pada peningkatan kualitas lulusan prodi TKJ SMK ROSMA.
\end{abstract}

Kata Kunci : Android, Development, Game, Sekolah Manengah Kejuruan.

Abstract

The increasing number of Android users in the community, encourages the industry to apply some of its business processes through Android applications. This opportunity should be taken by education circles, especially Vocational High Schools (SMK). Vocational schools that have computer-based education programs can at least apply them to the curriculum. However, not all can implement it, this can be caused by the lack of computer specifications in schools, making it difficult to implement Android developer learning. Android Game Developer Training is one of the potentials to improve the competence of SMK students. In this activity, the partner of the android game application development training is the Computer Network Engineering (TKJ) study program at SMK ROSMA KARAWANG. The purpose of this activity is to provide a basic understanding of making Android game applications, so that they can develop the competence of TKJ study program students and increase the absorption of vocational graduates in industry. The results of this activity are in the form of an android game application product developed by the participants which can be installed on each participant's 
mobile phone. The implication of this activity is to increase students' interest in learning in the development of android base applications which have an impact on improving the quality of graduates of the TKJ SMK ROSMA study program.

Keyword : Android, Development, Game, Vocational High School

\section{PENDAHULUAN}

Pengguna android di Indonesia tercatat semakin meningkat dan paling unggul diantara iOS, Samsung, Windows, Nokia. Statcounter mencatat 91,42\% pengguna Andorid, 8,39\% pengguna iOS, 0,08\% pengguna Samsung, 0,04\% pengguna Windows, 0,02\% Unknown dan 0,01\% Nokia Unknown(Statcounter, 2021). Sedangkan menurut data Statista.com mencatat bahwa pengguna android meningkat tajam sampai $92,14 \%$, pengguna iOS sebanyak $7,63 \%$ sedangkan sisanya adalah pengguna Blecberry, Sony Erricsson, Nokia unknown, SymbianOS, Samsung, Tizen, Linux, Series 40, Windows, dan unknown(Statista.com, 2021). Data tersebut, memberikan peluang kepada industri untuk dapat mengintegrasikan proses bisnisnya kedalam operating sistem android. Peluang ini, dapat menjadi kajian bagi Sekolah Menengah Kejuruan(SMK) khususnya yang memiliki program studi base komputer.

Kompetensi dalam mengembangan aplikasi berbasis android dapat menjadi salah satu persyaratan dalam menjadi seorang software engineer. Pengembangan kompetensi lulusan dengan skill development aplikasi android sangat mendukung peningkatan penyerapan lulusan SMK di Industri.

Pada kegiatan pelatihan development aplikasi game android ini, mengundang mitra dari program studi Teknik Komputer Jaringan(TKJ) SMK ROSMA KARAWANG. Kegiatan ini bertujuan memberikan pembekalan kepada siswa program studi TKJ dengan keahlian development aplikasi game android yang dapat di lanjutkan dengan pengembangan aplikasi lain berbasis android. Sehingga lulusan, dari program studi TKJ dapat mudah terserap di Industri dan memberikan kesempatan lulusan memiliki profesi menjadi serang software engineer. Kegiatan ini tentunya dapat berimplikasi pada peningkatan mutu lulusan program studi TKJ SMK ROSMA KARAWANG. Beberapa penelitian terdahulu membuktikan bahwa aplikasi android dapat dimanfaatkan dalam menyelesaikan masalah - masalah yang diindustri maupun bidang lain diantaranya (Ham \& Hafizah, 2021), (Azima \& Laila, 2020), (Egy Muhammad Rianof, Bambang P. Adhi, \& Z.E. Ferdi F. Putra, 2020), (Wismantoro \& Widiatmoko, 2021), (Muchlis, 2020). 


\section{METODE}

Pelatihan ini menghadirkan dua pemateri yang berasal dari STMIK Rosma. Pemateri pertama adalah Rahmat Gunawan, Ketua Program Studi Manajemen Informatika STMIK Rosma, pemateri kedua adalah Suresh Rafimera, Mahasiswa Manajemen Informatika STMIK Rosma. Kegiatan pelatihan developement game android ini, di mulai dengan melakukan survei awal untuk menelusuri pemahan tentang logika pemrograman, kemudian dilanjut dengan penjadwalan kegiatan bersama mitra yaitu program studi TKJ SMK ROSMA. Sebelum pelaksanaan, dilakukan penyusunan materi yang disesuikan dengan hasil survei awal. Selanjutnya adalah kegiatan pelaksanaan dan evaluasi. Pada tahap evaluasi dilakukan dengan memberikan studi kasus kepada peserta untuk memodifikasi aplikasi sesuai arahan. Kegiatan ini diikuti oleh 35 peserta yang terbagi menjadi 2 kelas.

\section{HASIL DAN PEMBAHASAN}

Kegiatan pelatihan development game android ini, dilaksanakan pada tanggal 6, 8 dan 9 maret 2021. Hari pertama diisi dengan penyajian materi terkait logika pemograman, yang bertujuan untuk memberikan pemahaman logika pemogram yang mendukung dalam pengembangan aplikasi berbasis android.

Hari kedua diisi dengan penyajian materi tentang desain interface aplikasi. Peserta diminta membuat desain interface sesuai yang dicontohkan oleh pemateri. Dengan proses mencontoh ini, diharapkan peserta dapat memahami penggunaan tools pada aplikasi. Dan hasilnya memperlihatkan seluruh peserta sukses meniru apa yang disajikan oleh pemateri. Setelah siswa memahami desain interface dilanjut dengan proses inti memasukkan logika pemograman kedalam desain tersebut.

Hari ketiga diisi dengan evaluasi terhadap pemahaman peserta. Peserta oleh pemateri diminta untuk mengembangkan aplikasi game android sesuai dengan studi kasus. Diawal evaluasi, beberapa peserta kesulitan menerapkan, namun dengan pendampingan dari pemateri, akhirnya peserta dapat menyelesaikan studi kasus yang diberikan. Berdasarkan hasil evaluasi, ada peningkatan pemahaman, hal ini terbukti dengan peserta telah berhasil membuat aplikasi game android yang dapat dinstal pada mobile phone masing - masing.

Dokumentasi pelaksanaan webinar tersaji pada gambar dibawa ini : 
Abdimas : Sistem dan Teknologi Informasi

Vol. 01, No. 01, Juni 2021:17-22

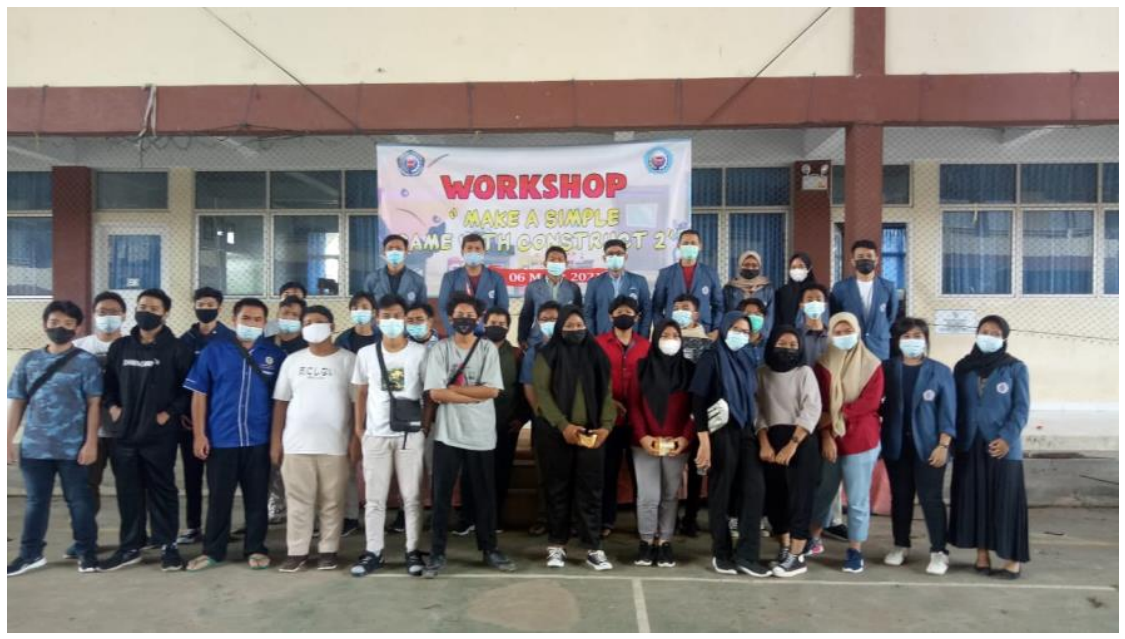

Gambar 1 : Peserta Pelatihan

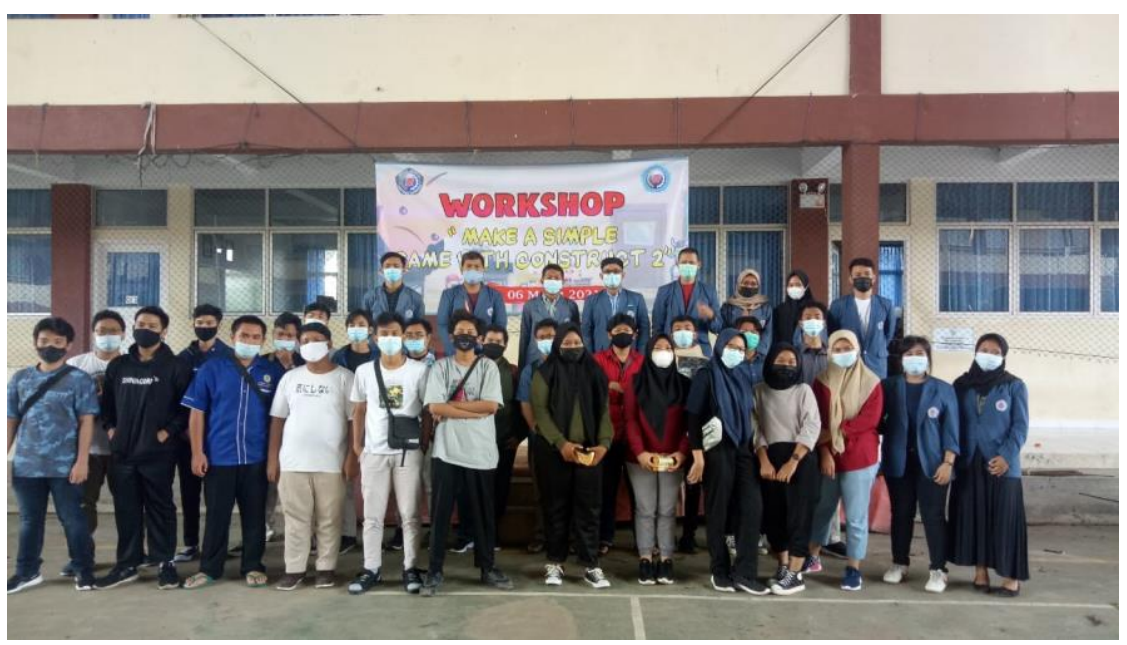

Gambar 2 : Peserta Pelatihan

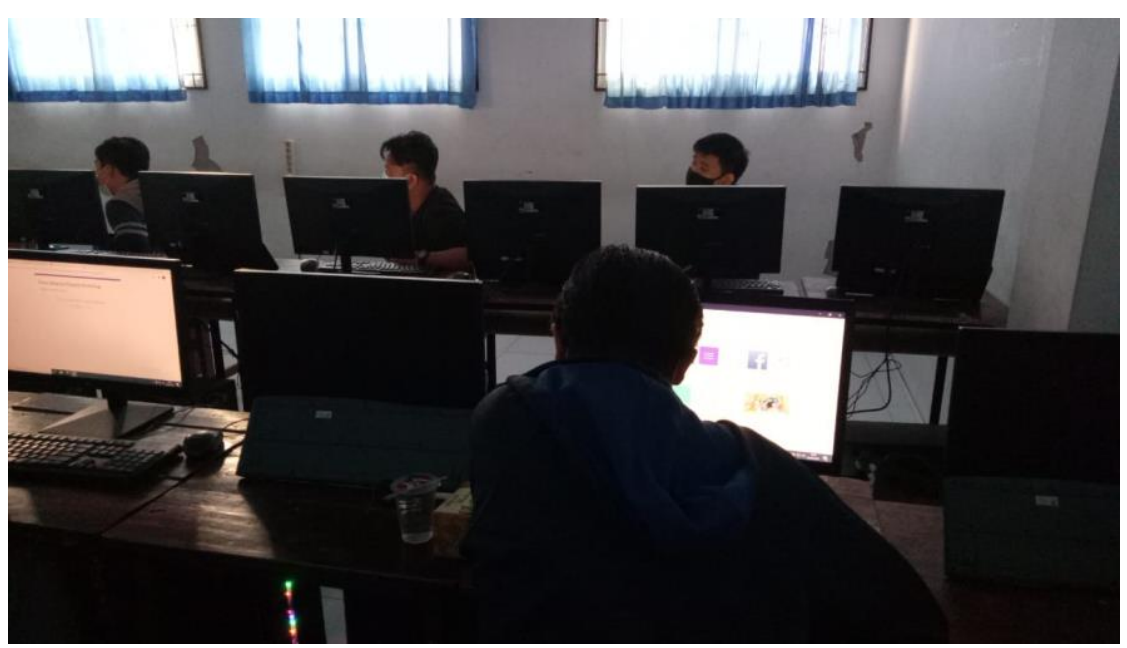

Gambar 3 : Peserta Melakukan Praktik 


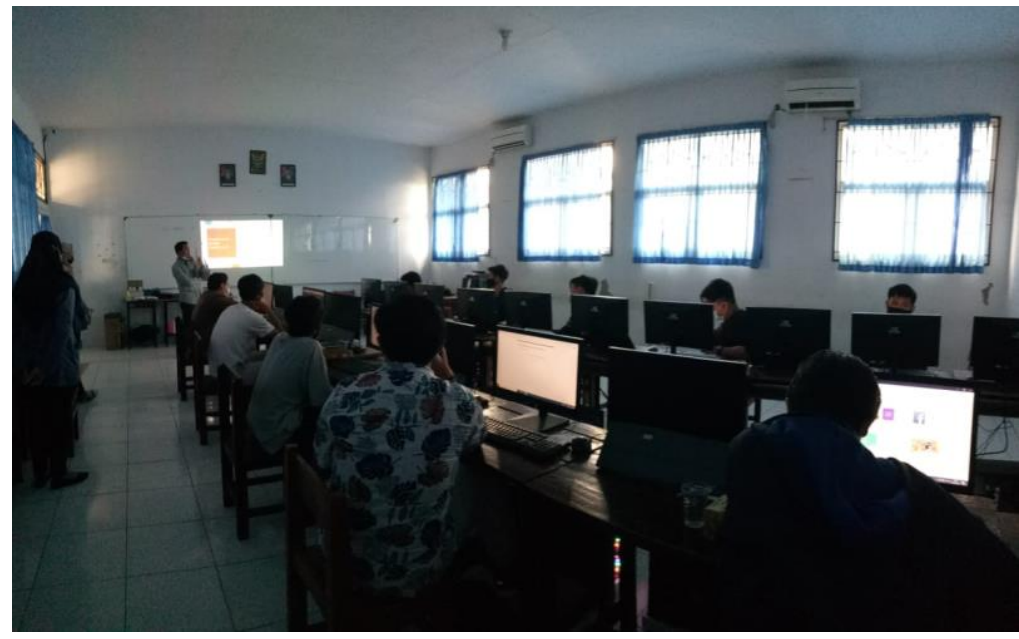

Gambar 4 : Peserta Melakukan Praktik

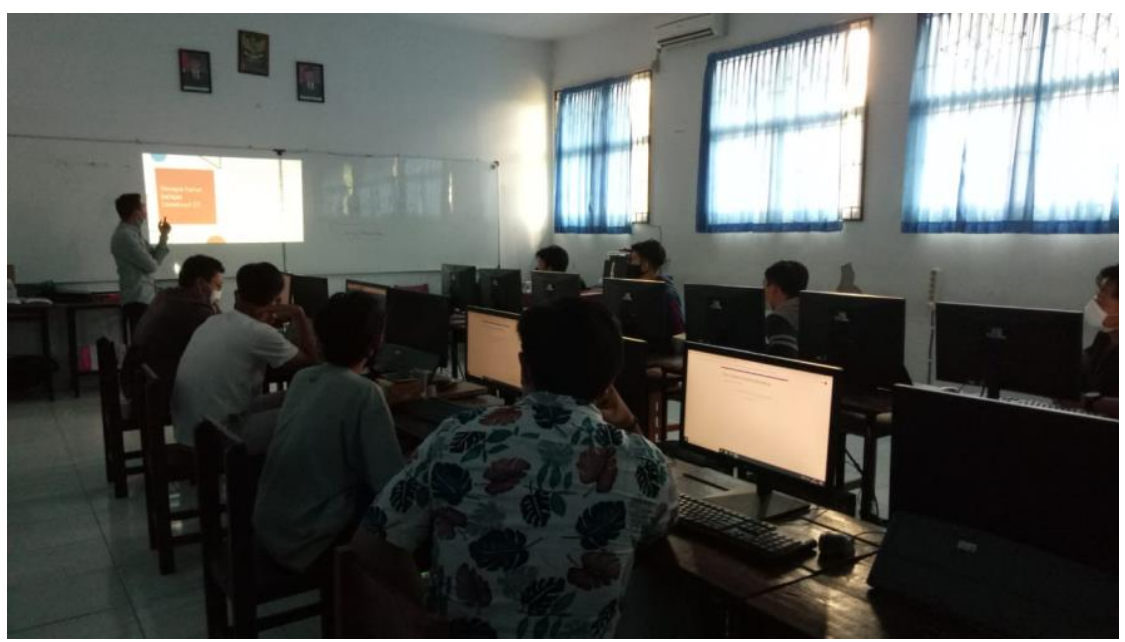

Gambar 5 : Peserta Melakukan Praktik

\section{KESIMPULAN DAN SARAN}

Pelatihan development aplikasi game android dengan mitra prodi TKJ SMK ROSMA, berjalan dengan lancar, dari tahapan survei awal, penjadwalan, penyusunan materi, pelaksanaan dan evaluasi. Kesenangan peserta dalam mengikuti pelatihan ini terlihat dari apa yang dihasilkan yaitu aplikasi game android. Perasaan senang ini, mendorong peningkatan peminatan dalam developer aplikasi android. Melalui kegiatan ini, peserta mendapatkan pengalaman mengembangkan aplikasi android yang dapat dikembangkan dengan mengambil studi kasus tertentu. Kegiatan ini juga dapat berimplikasi pada SMK ROSMA KARAWANG yaitu meningkatnya mutu lulusan, sehingga dapat mudah terserap di dunia industri atau dapat juga lulusannya berwirausaha dengan profesi developer android. 


\section{UCAPAN TERIMA KASIH}

Ucapan terima kasih disampaikan kepada UPT TIK SMK ROSMA yang telah memberikan ruang kepada kami, serta Kepala Sekolah, Guru dan Siswa Program Studi Teknik Komputer dan Jaringan SMK ROSMA KARAWANG yang telah berperan dalam kegiatan ini.

\section{REFFERENCE}

Azima, M. F., \& Laila, S. N. (2020). Rancang Bangun Aplikasi Kamus Bahasa dan Aksara Lampung Dialek A dan Dialek O Berbasis Android. Teknika, 14(1), 21-29. Retrieved from https://jurnal.polsri.ac.id/index.php/teknika/article/view/2085

Egy Muhammad Rianof, Bambang P. Adhi, \& Z.E. Ferdi F. Putra. (2020). Pengembangan Aplikasi M-Commerce Pada Toko Optik Menggunakan Android Studio. PINTER: Jurnal Pendidikan Teknik Informatika Dan Komputer, 4(2), 15-18. https://doi.org/10.21009/pinter.4.2.3

Ham, N., \& Hafizah, A. (2021). SOROTAN PERKEMBANGAN PEMBANGUNAN APLIKASI ANDROID JUZ ' AMMA VERSI BAHASA MELAYU DARI TAHUN 2016-2020 THE DEVELOPMENT OF JUZ' ' AMMA ANDROID APPLICATION IN MALAY LANGUAGE VERSION : AN OVERVIEW OF 2016 TO 2020 ADVANCEMENT. Journal of Ma'alim Al-Quran Wa Al-Sunnah, 17(1), 42-55.

Muchlis, N. F. (2020). Monitoring Keaktifan Mahasiswa Selama Perkuliahan Online Pada Masa Pandemi Covid-19 Melalui Aplikasi Absensi Dan Penilaian Berbasis Mobile. JIRA: Jurnal Inovasi Dan Riset Akademik, 1(4), 350-359. https://doi.org/10.47387/jira.v1i4.59

Statcounter. (2021). Pengguna Mobile Phone. Retrieved June 9, 2021, from Statcounter website: https://gs.statcounter.com/os-market-share/mobile/indonesia

Statista.com. (2021). Mobile Operating System. Retrieved June 9, 2021, from https://www.statista.com/statistics/262205/market-share-held-by-mobile-operatingsystems-in-indonesia/

Wismantoro, Y., \& Widiatmoko, K. (2021). Pendampingan Membangun Portal Aplikasi Android Gamelan Wirun untuk Memperluas Pasar Gamelan. Abdimasku, 4(2), 184-190. 